A middle-aged, cheerful fellow walked in just after me, carrying a large pot. "Beef barley," he told the patient's wife. "There's space in the fridge," she replied. He deposited the soup and left with a nod and a kind smile.

Between mouthfuls of waffles, I made some suggestions for medications and phoned the pharmacist. I spoke with the patient, who awoke from a snooze on the couch to smile warmly at his wife and submit to a brief examination.

I didn't need to know much; he had no pain, was scared, but trusting, wanted to stay home until he died and felt better with tiny doses of morphine and the occasional sleeping pill. I would come back on the weekend for another visit.

Before the next visit, I was called again - this time to declare the patient deceased and fill out the relevant paperwork.

The house was sad, but peaceful, and his wife still wore her dignity and tenderness - perfectly paired with overalls and a t-shirt. A neighbour sat in the front yard with a phone, working her way through a list of names and the coffee pot was rumbling again.

As I left, I reflected on this little town, where isolation breeds a kind of

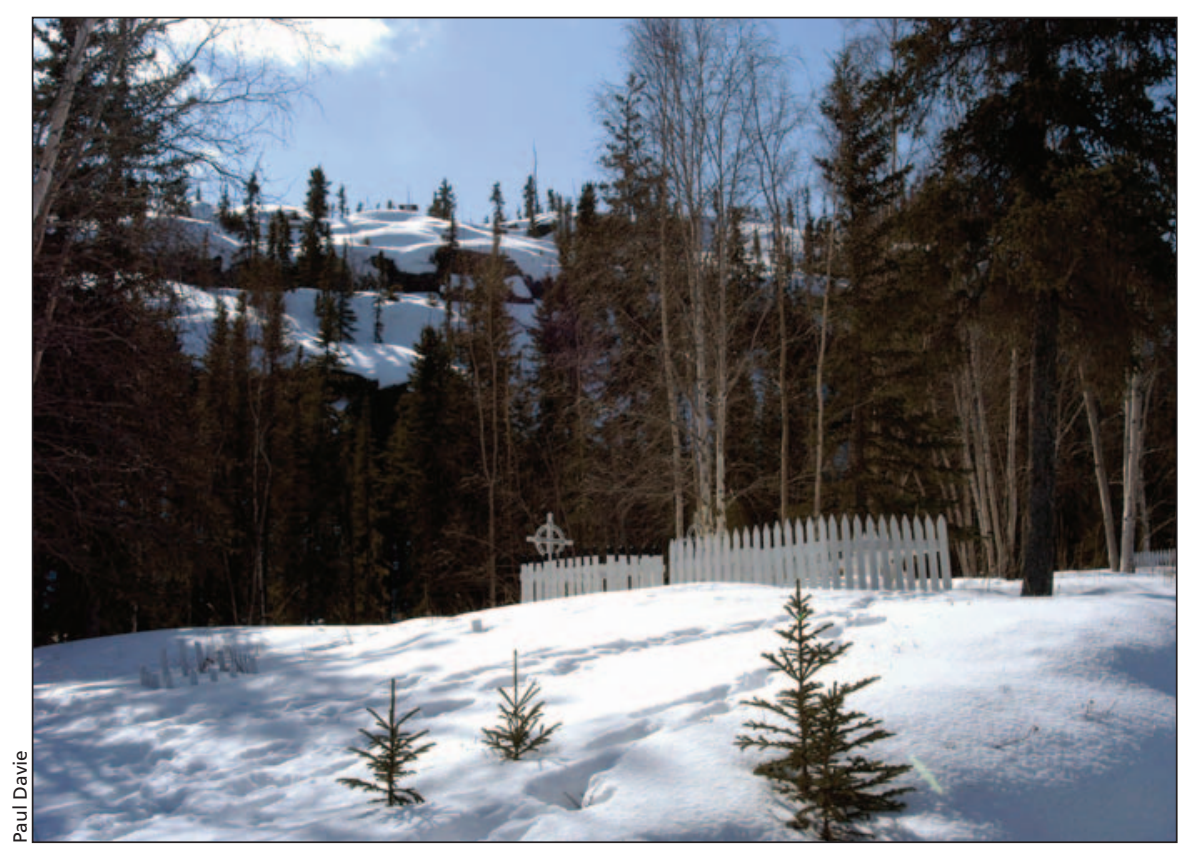

practical connection between neighbours and among health care workers. No one lives more than 15 minutes away and words are not wasted when there is soup to deliver or a prescription to pick up. Many of my patients list neighbours as their "next of kin" on hospital records. And as for the Home Care nurses - well, they know where I live, and they'll deliver an internist to your kitchen table if they think she can be of assistance.

\section{Amy Hendricks MDCM \\ Internal medicine \\ Yellowknife, NWT}

This article was previously published July 3, 2008, on Dr. Hendricks' CMAJ blog (http://cmajblog.blogspot.com/).

\title{
Final exam
}

I pronounced my first patient dead today, a patient whom I had never met. I was on call for our hospitalist team and received a page telling me that she had passed away in her sleep. I vaguely remembered her story from rounds - a very elderly woman who had suffered a massive stroke a month ago and never regained full consciousness - but in my first 3 days on service our team had not gathered at her bedside. Her death was expected, but not imminent. My - sign-out list said do not resuscitate: no chest compressions, no intubation, no intensive care admissions. Her family had told us of her wish to pass away without the fanfare of a code.

In medical school we were not given the specifics of how to pro- nounce a patient dead. Perhaps it was false optimism - our patients were not going to die - but more likely 4 years were not sufficient to tackle the objectives for living patients, much less the deceased. Walking down the

\section{At that moment I realized, my role was a function of formality.}

hallway from my call room, I wondered what I should do when I arrived at the bedside. I remembered the neuro exam of a comatose patient and thought of the procedures to assess brain function - but the coma exam assumes the patient is still alive. Should I walk faster? Run? I length- ened my stride, but was thankful the hospital was built wide instead of tall.

When I got to the floor, the patient's nurse, Marisol, wearing her 20-year golden RN pin, was waiting for me. These were the letters I looked for

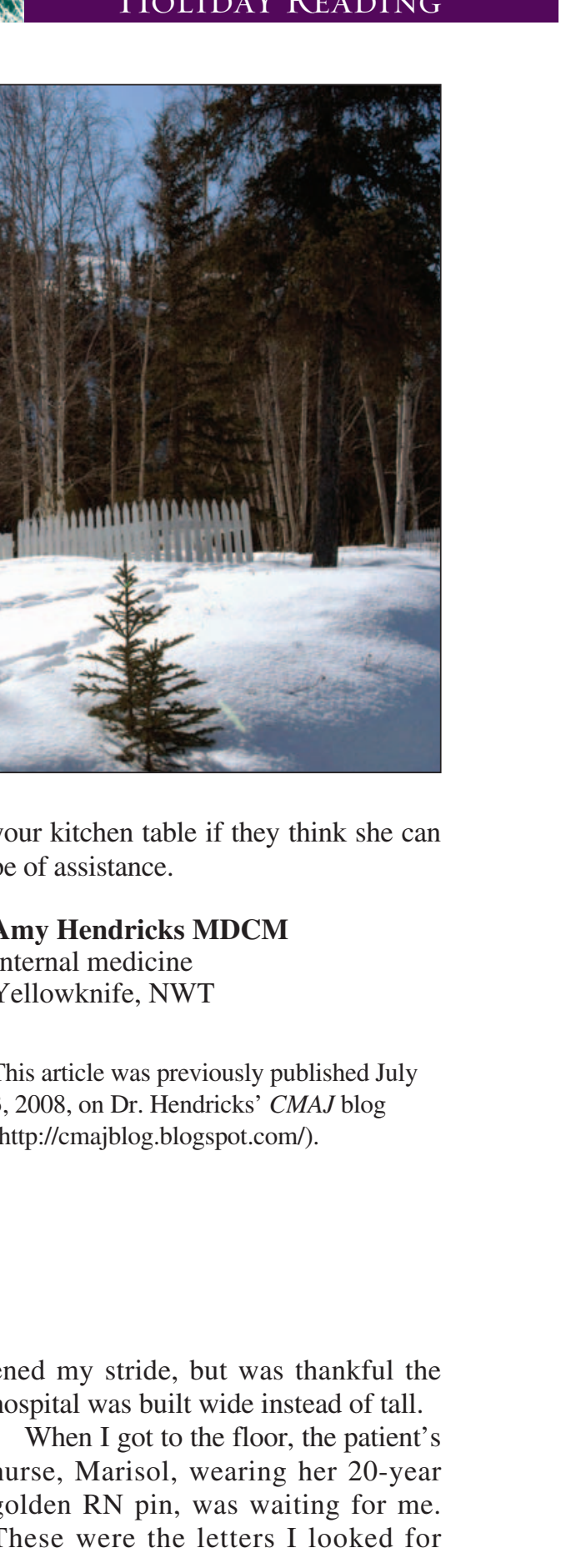




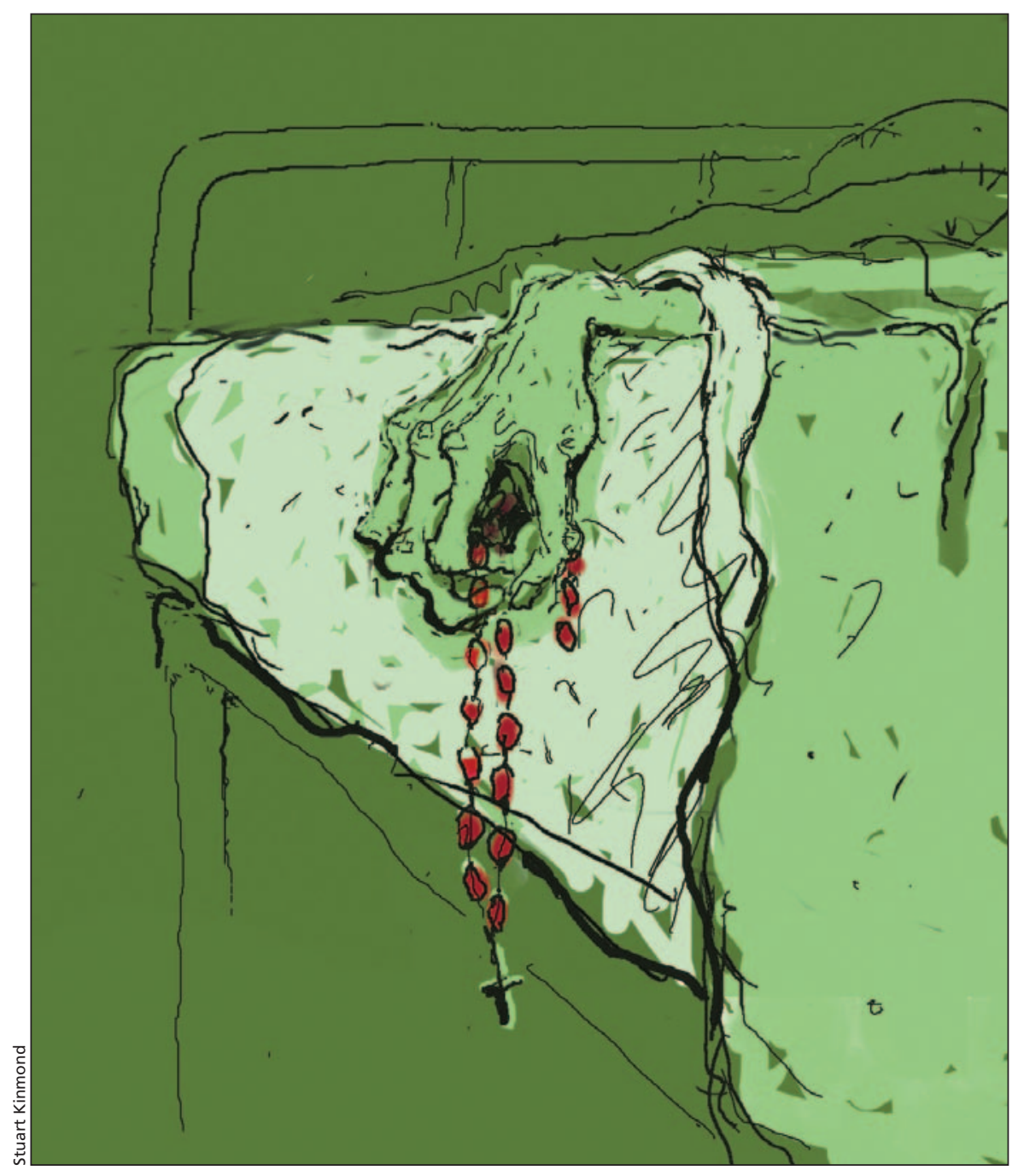

refused to take her medications. It was like watching Mary Poppins with a small child; witnessing this intervention, even I was tempted to drink the bitter potassium elixir.

Marisol, chart in hand, told me the patient's time of death and family's phone number. They do not know, she said. You can call after you see Ms. Smith. She is in room 108.

Suddenly feeling inadequate and sure I was at risk of sending a living, breathing patient to the morgue, I asked Marisol to come with me. I used the explanation I had used at least a hundred times in these first weeks of residency: I have never done this before. I went to the utility room to get the ophthalmoscope - my plan was to at least assess pupil reactivity. Marisol looked over and quietly said, That won't be necessary. At that moment I realized, my role was a function of for-
20 beating hearts this day alone and thousands in my brief career, the absence of sound made me linger, repositioning the bell on her chest, but hearing only hollowness.

As I palpated her carotids for completeness - her neck warmer than her hands - I raised my eyes to her face. Her forehead lines were unappreciable and eyelids, without eyelashes, softly closed, but her cheeks, or lack thereof, told me more than any other portion of the exam that she had passed. Falling over her cheekbones, her skin sank inward towards her mouth, taut and rounding her jaw like the face of an ice mummy, frozen in the Andes for 600 years. The prominence of her facial bones reminded me of the teachings of many religions: the body is a temporary home for our souls.

At the bedside, it was clear this body's soul had left and I began to feel embarrassed, imagining this soul watching my naive exam and hearing my thoughts. More likely, however, this soul had departed soon after she breathed her last quiet breath alone in this bland hospital room, eager to move on from this vector that had been motionless in recent days.

Marisol patiently looked on and when I asked if there was anything else to be done, she lowered the bed and placed the sheets back over the body as though she were tucking in a child. Marisol dimmed the lights and I followed her out of room, where she handed me the chart, the death certificate and Ms. Smith's son's phone number.

\section{Catherine Varner MD}

Family and Community Medicine University of Toronto

Toronto, Ont. curled over the cross. I felt her wrists - no pulse. Her skin rolled easily over her tendons and blue veins, different from our cadaver's waxy and formalinthick skin in anatomy lab. There was no difference in temperature between the sheets, the air and her limbs, all equally cool.

I placed my stethoscope on her chest, heard nothing and, recalling intensive care unit codes when heart electricity fibrillated on monitors, I listened longer for any signs of cardiac quivering. Having heard at least
"Start at once a bed-side library and spend the last half hour of the day in communion with saints of humanity." - Sir William Osler

From Aequanimitas: With Other Addresses to Medical Students, Nurses and Practitioners of Medicine (Philadelphia: P. Blakiston's Son \& Co.; 1906). 